\title{
Spinal Extradural Meningeal Cyst: A Case Report
}

\author{
Seul-Kee Lee, Jae Young Kim, Ju-Hwi Kim, Bong Ju Moon, Jung-Kil Lee, and Soo-Han Kim* \\ Department of Neurosurgery, Chonnam National University Hospital, Chonnam National University Medical School, Gwangju, Korea
}

A 19-year-old male presented with the chief complaint of progressive back pain and bilateral buttocks pain. Computed tomography revealed a spinal canal widening and remodeling at the level of T11-L1 (Fig. 1A). Magnetic resonance imaging (MRI) revealed an extradural cystic lesion in the dorsal aspect of the thecal sac at the level of T11-L1. The cystic lesion had several septations and the cystic fluid showed a signal intensity similar to that of cerebrospinal fluid. (Fig. 1 B-D).

The patient underwent osteoplastic laminotomy at the levels of T12 and L1. The cystic wall was thin and transparent in the microscopic view (Fig. 1E). Dissection of a multilayered transparent membrane and partial removal of the ventral cystic wall revealed a communicating defect at the dural sleeve near the right $\mathrm{T} 12$ rootlet. Herniated rootlets were identified within the dural defect and the defect was closed with primary suturing without sacrifice or injury of the rootlets (Fig. 1F, G). Pathological examination demonstrated an arachnoid cyst mixed with a flattened epithelium. On the basis of these findings, the lesion was diagnosed as an extradural meningeal cyst. The six month follow-up plain radiography and MRI showed no recurrence and the patient was satisfied with the outcome and had no neurological complications. (Fig. 1H, I).

Spinal extradural meningeal cysts are rare. In the past, the entire cyst was removed for treatment, as the etiology was unclear. ${ }^{1}$ The cause of a meningeal cyst is now thought to be fluid accumulation due to a dural defect after trauma. ${ }^{2}$
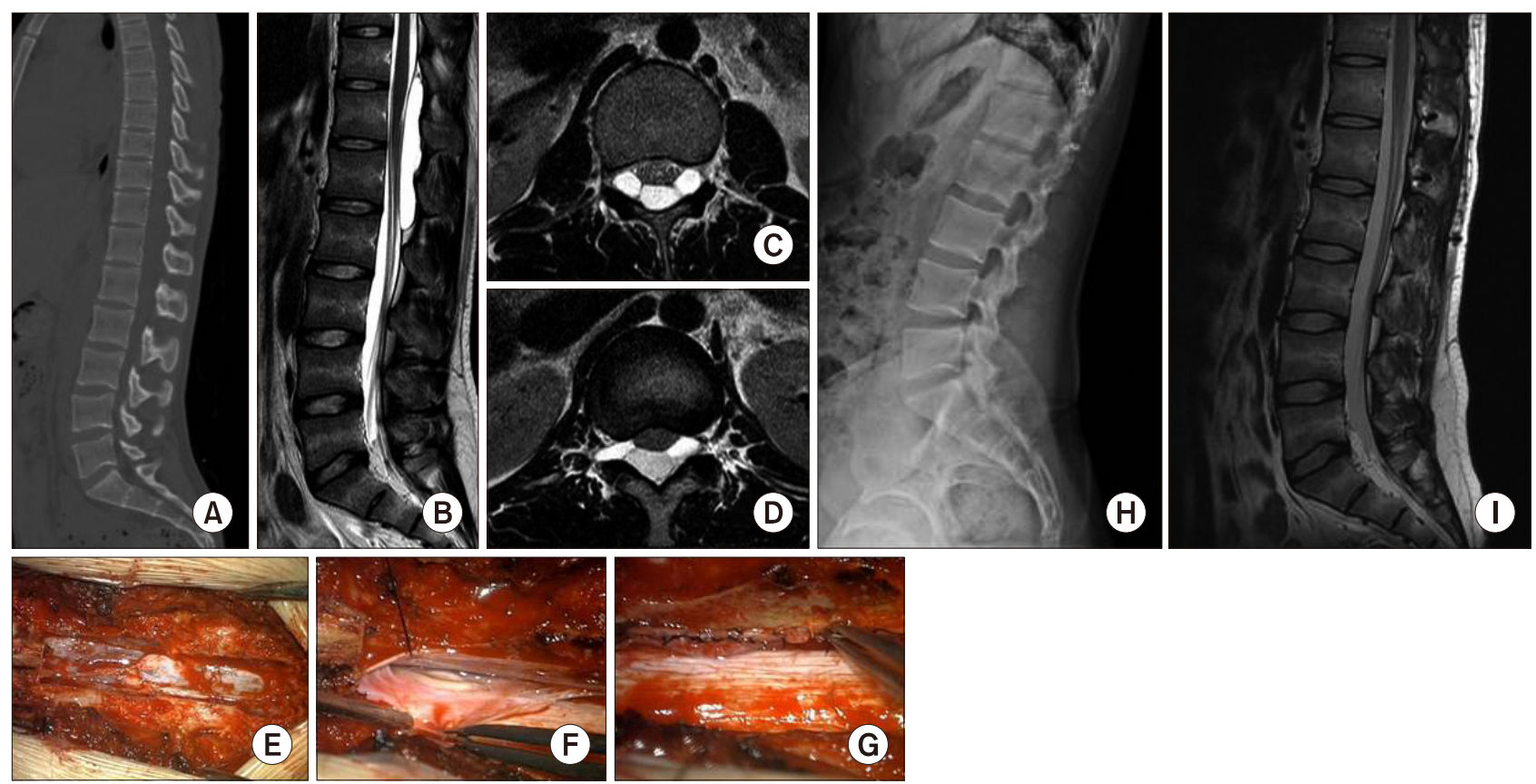

FIG. 1. Lumbar spine CT (A), sagittal T2-weighted MRI (B), axial T2-weighted MRI (C, D). Intraoperative photographs. After laminectomy (E), defect at dural sleeve near right T12 rootlet (F), primary closure of dural defect (G). 6-month follow-up after osteoplastic laminotomy and cyst removal. Plain lumbar radiography $(\mathrm{H})$, sagittal T2-weighted MRI (I).

\section{Corresponding Author:}

Soo-Han Kim

Department of Neurosurgery, Chonnam National University Hospital, 42 Jebong-ro, Dong-gu, Gwangju 61469, Korea Tel: +82-62-220-6606 , Fax: +82-62-224-9865, E-mail: soohan@jnu.ac.kr
Article History:

Received December 7, 2018 Revised December 25, 2018 Accepted December 26, 2018 
The treatment goal has also changed to primary closure of the dural defect through hemilaminectomy or laminotomy, removing only part of the ventral cystic wall. ${ }^{2,3}$ With this approach, the cyst can be treated less invasively, and an excellent treatment outcome can be expected. Therefore, we suggest that disruption of the communicating tract through primary closure of the dural defect is the key to management of an extradural meningeal cyst.

\section{ACKNOWLEDGEMENTS}

This work was supported by a research grant from the Research Institute of Medical Sciences, Chonnam National University (2010-CURIMS-DR001).

\section{CONFLICT OF INTEREST STATEMENT}

None declared.

\section{REFERENCES}

1. Chang IC. Surgical experience in symptomatic congenital intraspinal cysts. Pediatr Neurosurg 2004;40:165-70.

2. Lim MS, Khalil A, Okafo U, Dunlea O, Kaar G. Hemilaminectomy for large spinal extradural meningeal cysts: a case report and review of surgical techniques. Ann R Coll Surg Engl 2016;98:e162-4.

3. Sangala JR, Uribe JS, Park P, Martinez C, Vale FL. Nerve root prolapse into a spinal arachnoid cyst--an unusual cause of radiculopathy. Clin Neurol Neurosurg 2009;111:460-4. 